\title{
The Influence of Traditional and Modern Cultures on Zhang Ailing's Creation
}

\author{
Tao Jun
}

Nanchang Institute of Science and Technology, Nanchang, Jiangxi 3300001

\author{
Keywords: Traditional Culture, Modern Culture, Writing Technique
}

\begin{abstract}
Zhang Ailing grew up in Shanghai, where Chinese and Western culture hit the hardest in the 1920s. Her deep roots in traditional culture promoted she grow up and read classical poetry. After studying abroad, her mother was greatly influenced by Western culture, exerting a great effect on Zhang Ailing after returning to China. These legendary personal experiences and knowledge structures make her equipped with the accumulation of Chinese traditional culture and the awareness of Western modern culture, which has a profound impact on Ailing Zhang's later works. Her works often reflect the combination of Chinese traditional culture and modern western culture. However, her works reveal the infiltration of Western modern culture. Her novel has a profound "modernity" in feeling and expressing.
\end{abstract}

\section{Introduction}

Chinese traditional culture is Confucianism, Buddhism and Buddhism with Confucianism as the core. We are supposed to pay attention to the concept of filial piety and justice, three classes and five permanent ethics, patriarchal hierarchy, the golden mean concept. Since the beginning of its formation, Chinese traditional culture has deeply influenced people's basic necessities of life, social life, value orientation and other aspects for thousands of years [1]. However, the loud bang of May Fourth Movement inflicted heavy losses on China's traditional culture. The literati headed by Chen Duxiu, Hu Shih and Lu Xun fiercely opposed China's traditional culture and overthrew Kongjiadian. Chinese culture breaks down. Since the Opium War in 1840, China began to be reduced to a semi-colonial and semi-feudal society. [1] Western powers plundered China and also brought Western civilization to China. China's traditional culture swayed in the European style of the United States. So since the May 4th Movement, Chinese culture began to have modern consciousness. Emphasize the people's wake, the pursuit of freedom, the concept of democracy enjoys popular support. The constant collision and blending between Chinese traditional culture and modern Western culture present a new attitude that affects people's daily life, their ideas and values, and other values.

Zhang Ailing grew up in Shanghai, she attended the Santa Maria's School of Western Education, and was admitted to the University of London in 1939, because of the war in Europe Zhanged to Hong Kong University, met a lot of foreign students and overseas Chinese businessmen [2]. Not only did she understand Western culture, she knew "listening to the bagpipe (bagpipe)" ("genius dream") or French modernist painting, but also gave her a sense of modern civilization. For example, she maintained a critique of the real life of China at that time and used the concepts of democracy and freedom from the West to examine China. Her works often reflect the combination of Chinese traditional culture and modern western culture [3]. However, her works reveal the infiltration of Western modern culture. Her novel has a profound "modernity" in feeling and expressing. These mainly come from the following aspects:

\section{From the Creative Theme}

The Opium War artillery fire opened the door to China, ceded Hong Kong and became a British colony. As one of the ports of commerce for the opening up of Shanghai, Shanghai also opened its door to the West. Zhang Ailing in addition to spending a few years in Hong Kong, her rest of the time was spent in Shanghai, western culture and urban civilization to her creation can not be 
underestimated [1]. Her novels mostly describe the life of the traditional family under the double attack of the old and the new civilizations. She has experienced unprecedented distress and perplexity in her writing of family life. Writing urban civilization and western culture has brought embarrassment to the new family. Cao Qijiao in the "Golden Lock" immersed himself in the stench brought by the capitalist world, and lost her possession of money but her mother's inherent nature. In the "Allure Love", the white tassel yearned for the happiness and fantasy of free love in the love of moisture to get rid of the family brought depression and depression. Her familiarity with urban life and her experience of living in Hong Kong led her to focus her attention on foreign market life and urban society in Shanghai and Hong Kong [3]. A large number of works depicting the city's tram trams, apartments, cafes, dance halls and so on. Small citizens follow the western lifestyle, wear dresses, live in houses, study abroad and so on. Everything in the city includes noisy downtown sounds and the taste of gasoline is full of her work. "Shen Xiang shavings - the first incense" write Ge Wei Long in the foreign field to become a social flower life.

\section{From the Creative Approach}

\subsection{Influenced by Freud, her works have a delicate and unique psychological description}

Zhang Ailing was deeply influenced by Western civilization, especially Freudian psychology theory for her writing a huge impact, many of her novels with a clear psychological analysis of the shadow. Freud divides the personality structure into "self", "self" and "super self". "I am" at the bottom of the personality structure. The "self" is always in the field of unconsciousness, follows the principle of happiness, and forces people to try to meet the demands of the pursuit of pleasure. From the point of view of society as a whole, these views often violate moral customs. As a result, a "self" of regulators emerged between "self" and social reality. The task of "self" is to respect the principle of reality and to help "self-realization" on this basis. "Self" should not only prevent over-repression to bring harm to people, but also avoid open clashes with social morality. The highest level of personality structure which is "super-self" is already the psychological mechanism that represents the interests of society [[2]. "Super-I" is always based on moral principles, social habits can not tolerate the "self" suppressed in the field of unconsciousness. In short, we can understand "self" as an indulgent passion, "self" as rational and prudent, and "super self" as a moral, honor and conscience. Freud also believes that every child has a tendency of secretly loving heterosexual parents. With the aid of the Oedipus story of killing his father and mother in ancient Greek mythology, this tendency is named "Oedipus" complex. Due to the incestuous nature of this tendency, since the demands of "self" are often contrary to social morality, "self" has been supervised and suppressed by "self" and "super ego", creating mental anxiety and tension. In order to alleviate this anxiety and tension, "self" has taken protective measures, including repression and sublimation. Repression means expelling these dangerous impulses out of consciousness so as not to cause dangerous actions; sublimation refers to putting these dangerous impulses and sentiments into the cultural activities allowed by morality, and turning them into elegant behavior. These thoughts of Freud have been reflected many times in Zhang Ailing's novels. "Shen Xiang crumbs second furnace incense" wrote the repression of sexual desire at the despair of suicide; "Jasmine Xiangpian" performance of the hero Nie Chuanqing not affectionate parents and denounced denunciation and denunciation of female students; "blockade" Write the martial law of the city during this particular time a pair of middle-aged men and women in the tram met subtle inner activities; "Heart Sutra" Xu Xiaolu wrote to his father's abnormal love. Ailing Zhang's psychoanalytic methods in the literary creation of skilled use of making her work poorly depicting the real character of the characters, the characterization of the psychological complex and thorough, to write these tragic life nuanced and heartbreaking[3].

\subsection{Create a strong image with a symbolic meaning}

Image is a combination of abstract ideas and vivid images. Although it is an ancient one, modernist novels generally pay attention to the creation of images. By searching for "objective 
contact objects" for ideology, finding "counterparts" for emotions, forming images and often arranging images, replaces the traditional narrative description of events and the reflection of the objective world. The connection between "meaning" and "image" is more secretive, more exotic, more abstract, and loads more content. Zhang Ailing draws heavily on the techniques of Western modern novels to make extensive use of images in his works. Xia Zhiqing in the "History of Modern Chinese Fiction" mentions: "The richness of images in her novels can be second to none in modern Chinese novelists." [2]Her image has a new category of the old and the old. Although her image is borrowed from the traditional images in ancient Chinese literature, her imagery mainly uses its image and the meaning is completely modern. For example, the image of "Moon" has been used in ancient times. However, Zhang Ailing's works repeatedly show a completely different meaning. Her moon incorporates a strong sense of Western modernity. Her image of the moon creates a desolate emotional tone. "The first incense," Ge Weilong's moon for a while, "a moon shadow shadow", "as if a fat white Phoenix, habitat in the corner of the road at the tree for a while, "yellow like jade satin on the embroidered when the drop a little bit of ash, burn a small piece of ", Qiao Qi's moon is" a group of blue shade of fire ";" second furnace incense ", the fine" Most of the moon, "' just like a silver water at the icebreaker, "and Luo Jie's moon is shedding" whimper flute-like Ching Fai ";" Love in the Fallen City " "Big and fuzzy," "Green gleam," and sometimes "just a hook white, like a frost on a glass window"; "Red Rose and White Rose", the planet in Ling Zhenbao is " Red Crescent ";" Half-Life ", the moon in the eyes of Shen Shijun" like a white lotus. " "Golden Lock" is the image of the moon to the extreme. Starting with the image of the moon to determine the tone of remembrance, so desolate desolate atmosphere enveloped the entire article. When the Qigao mother and son opium late at night talking about the curtain of the wife when the moon reveals the meaning of evil shy, into the Zhi Shou line of sight of the wife instead terrorist terror. From this we can see that the images in Zhang Ailing's works are not only to express mood or reflect emotions, but also to serve as symbols or metaphors of the core of the works, to condense the contents of the works, and to convey the writer's theme. She also created some brand new images of individual images. For example, "Jasmine Xiang Pian." Nie Chuanqing's mother Feng Bisheng, her life was concentrated in such an image: "She is embroidered on the screen of the birds eleven purple purple satin screen, weaving a stone in a white bird. Dark mold to the moth died dead also on the screen. "This has a wealth of suggestive, metaphorical and symbolic[3].

\subsection{The use of montage techniques.}

Born in Shanghai, home of "China Hollywood," Ailing Zhang lived in Shanghai for most of her adolescence and had extensive access to Chinese and foreign films and had a strong interest in the film. Therefore, in her works often show the "movie" tendency. Such as the use of montage techniques. Montage, as the basic means of expression of the art of film structure means, has been called the soul of the film. The conflicts in Zhang Ailing's novels are not intense and the plot is not complicated. The most appealing thing is the colorful images created by Seiko Pencil, rich images, vivid scenes and delicate details. They overwhelm the artistic space of the novel, the narrative process of the novel is often interrupted, the structure of the work deviates from the linear narration, and presents a block combination. Zhang Ailing in the works on the use of montage approach to details and details, paragraphs and paragraphs, scenes and scenes connected. This makes her a fictional jump in the novel, the connection to produce new meaning, beneath the surface contains a broader range of things. At the end of the "Golden Lock", Qiqiao explores the jade bracelet on his wrist and slowly pushes the bracelet down the scrawny arm until the underarm is pushed down,even a few years after being married, the bracelet only seize into a foreign ocean to the handkerchief. At the age of 18 to do the girl, tall and rolled up the blue and white shirt, revealing a pair of white wrist. " Skinny arm - white wrist, "axillary under the bracelet - the bracelet on the wrist, "a sharp contrast, each impact[3]. So that the expression of ideas, emotions have been strengthened. The original meaning of the three separate lenses, not only aging - a young time flies, but "with a gold flail" Qi Qiao to our heavy and desolate. It is also forcing audiences (readers) to compare these two situations and thus receive mutual supportive and mutually reinforcing roles. 


\section{From the Creative Concept of View}

From Ailing Zhang's living environment and life time, as well as her life experience and knowledge structure, it can be seen that she is deeply influenced by Western culture and accepted the influence of Western modernist and modernist writers. She advocates a free and democratic thinking, emphasizing women's self-awareness, concerned about the economic problems of life, women's issues and human vulnerability issues. This is reflected in her works which were embodied in the female consciousness.

\section{1. the female living predicament and alienation of the concentrated display}

Chinese traditional culture pays attention to three basic principles of the five men and women, the female images in the old novels are mostly male plaything. They have no "human" desires at all. They can only mold themselves into the mode of loyalty and virtues according to the male aesthetic. However, Zhang Ailing, who accepted Western modernist ideas, has a "human" consciousness in her novels.Cao Qiqiao's inner joy came from the little uncle Jiang Jize. She also had brilliant love, bathed in "thin music, thin joy." This psychological portrayal of feudal ethics has opened up the moral shackles that have lain over Chinese women for thousands of years and calls for the arrival of humanity. However, this is only a flash in the pan, her long-term repression vent to their children's body. Often called his son Zhang Bai night midnight smoking big smokes, to delay the solution to the daughter of Zhang An's only engagement in life. Over-pursuit of money and suppression of feudal ethics obliterated Qi Qiao's human nature and eventually distorted its mind. She is both a victim and a victim. Through Cao Qiqiao and Zhang Ailing, we should show us the rationality of the existence of female desire. Cao Qiaoqiao's desire for normal sexuality and pursuit of money are not fault by themselves. Under the pressure of male-centered social ethics, she can not speak of her own existence as a "human being," so she is forced to put her loneliness, get yourself into the male mainstream society, like all the men around you, ripped your face to fight for property, desperate to get money, and far from love. Only in this way, she survived the gap between feudal ethics, though she wanted to transform her into an ugly man. Cao Qiao lost the normal desire, only a walking corpse[2].

\subsection{The desalination and deconstruction of the traditional male image}

Ailing Zhang clearly understands that civilization in present-day times is a civilization of men, and that women's lives in this civilization are "much more bitter than men." It is the cultural environment of the male center that forces women to become "women." At the same time, she also found that women themselves can not take a certain responsibility, "just blame others is not enough." Although the process of social development can not be controlled by non-personal forces, there is "always an active ingredient" in the concrete stage of development. Therefore, in order for women to face men in an equal manner, it is necessary to deconstruct traditional masculine images in order to establish women's independent self-personality. Based on this very modern sense of women and a deep sense of self-examination, Zhang Ailing conscientiously desalinates the male image in the novel and resolves the traditional upright and stalwart male image, thus eliminating the sacred centrality of men in women. Fan Liu's original appearance in The Love of Allure was arranged as a concubine, which in itself is figuratively humble and culturally rootless. This made Vanuatu lose the opportunity to "stand alone" from the outset. Sure enough, in the novel, Van Liu Yuan completely gone[3].

The courage and perseverance of the traditional masculine image and the humbleness and cowardice everywhere make it impossible for even the fringed woman, who is a fringe, to send a message of "conservative people like me, Pro, remarried from the body 'miles! You are such a free man, you can not call the shots, who is the Lord for you? "

\section{Conclusions}

In summary, Ailing Zhang is a wonderful flower in modern China, with her unique fragrance to 
attract every reader who loves her. This is due to her keen insight into the decline of culture and the society from the perspective of modern civilization.

\section{References}

[1] Zhu Zhixiu. Effects of Western Culture on Zhang Ailing's Novels [J]. Journal of North University of China, 2006, 22 (6): 29-33.

[2] Feng Lingyun. The Intertwining of Chinese Traditional Culture and Western Culture in Zhang Ailing's Novels [J]. Writer, 2008 (18): 19-20.

[3] Li Fang. On the impact of Chinese and Western cultures on the creation of Zhang Ailing [J]. Times Literature, 2011 (3): 203-204. 